\title{
Bilateral and simultaneous cystoid macular edema associated with latanoprost use: report of two cases
}

\author{
Edema macular cistóide bilateral e simultâneo associado com \\ o uso de latanoprost: relato de dois casos
}

\author{
Oswaldo Ferreira Moura Brasil ${ }^{1}$ \\ Maria Vitoria Moura Brasil ${ }^{2}$ \\ Marcelo Palis Ventura ${ }^{3}$ \\ Hugo Soares Maia ${ }^{4}$
}

\begin{tabular}{|l|}
\hline ABSTRACT \\
\hline Cystoid macular edema is an uncommon, but well known, side effect of \\
latanoprost. Two cases of bilateral and simultaneous cystoid macular \\
edema associated with latanoprost use are described, which complete \\
resolution of the edema is observed upon drug discontinuation.
\end{tabular}

Keywords: Macula lutea; Macular edema; Glaucoma; Prostaglandin F, synthetic; Case Reports; Human; Adult
Work carried out at Instituto Brasileiro de Oftalmologia (IBOL) - Rio de Janeiro.

' Retina and Vitreous Service, Instituto Brasileiro de Oftalmologia - IBOL, Rio de Janeiro (RJ) - Brazil. Instituto da Visão, Universidade Federal de São Paulo UNIFESP São Paulo (SP) - Brazil.

${ }^{2}$ Glaucoma Service, Instituto Brasileiro de Oftalmologia - IBOL - Rio de Janeiro (RJ) - Brazil. Instituto da Visão, UNIFESP - São Paulo (SP) - Brazil.

${ }^{3}$ Glaucoma Service, Instituto Brasileiro de Oftalmologia - IBOL - Hospital Universitário Antônio Pedro, Universidade Federal Fluminense - HUAP - UFF - Rio de Janeiro (RJ) - Brazil.

${ }^{4}$ Retina and Vitreous Service, Instituto Brasileiro de Oftalmologia - IBOL - Rio de Janeiro (RJ) - Brazil.

Correspondence Address: Oswaldo Ferreira Moura Brasil. Praia de Botafogo, 206 - Rio de Janeiro (RJ) CEP 22250-040

E-mail: dico@unisys.com.br

Recebido para publicação em 27.10.2008

Última versão recebida em 08.10 .2009

Aprovação em 17.12.2009

\section{INTRODUCTION}

Latanoprost is a prostaglandin analogue that reduces intraocular pressure by increasing uveoscleral outflow. Since its introduction in 1996 it has been widely used to treat glaucoma and ocular hypertension, and several ocular side effects have been reported including hypertrichosis, increased eyelash pigmentation, hypotony, choroidal effusion, iritis, anterior uveitis and cystoid macular edema (CME). Nevertheless, latanosprost is rarely discontinued due to one of its side effects ${ }^{(1)}$.

The prostaglandin analogues may be associated with retinal bloodbarrier breakdown and CME has been reported as a side effect of latanoprost in numerous case reports, usually in association with risk factors such as aphakia and opened posterior capsule. The incidence of CME associated with latanoprost therapy is considered to be very low ${ }^{(2)}$.

Two cases of bilateral and simultaneous CME associated with latanoprost are described, which complete resolution of the macular edema is observed following discontinuation of the drug.

\section{CASE REPORTS}

Case 1

A 60 year-old male with severe primary open-angle glaucoma treated with dorzolamide-timolol solution $\left(\mathrm{Cosopt}^{\mathrm{TM}}\right)$ in both eyes (OU). The patient had history of cataract surgery with intraocular lens (IOL) implantation 3 years before and yag-laser capsulotomy 1 year later in OU. Bestcorrected visual acuity was 20/40 in the right eye (OD) and 20/150 in the left eye (OS). Intraocular pressure (IOP) was $20 / 21 \mathrm{mmHg}$. Latanoprost $\left(\mathrm{Xalatan}^{\mathrm{TM}}\right)$ was then added to the treatment and IOP was reduced to $12 / 13 \mathrm{mmHg}$ one month later. Three months after starting latanoprost the patient complained of reduced vision in OU, and best-corrected visual acuity was $20 / 100$ in OD and 20/400 in OS. IOP was $6 / 8 \mathrm{mmHg}$ at this time. Fluores- 
cein angiography disclosed CME in OU (Figure 1A and 1B) and latanoprost was discontinued, being replaced by brimonidine (Alphagan- $\mathrm{P}^{\mathrm{TM}}$ ). One month later vision improved to 20/40 in OD and 20/150 in OS, which was equal to baseline. IOP raised to $14 / 15 \mathrm{mmHg}$ and remained stable throughout the follow-up. A few months later a control fluorescein angiography was performed and the CME was gone (Figure $1 \mathrm{C}$ and $\mathrm{D}$ ).

\section{Case 2}

A 85 year-old female came in for a second opinion about glaucoma diagnosis. She had been diagnosed with primary open-angle glaucoma for 30 years, but was not currently using any anti-glaucomatous medication. The patient had previous cataract surgery with IOL implantation 10 years before and yag-laser capsulotomy 1 year later in OU. Bestcorrected visual acuity was 20/30 in OD and 20/25 in OS. IOP was $22 / 28 \mathrm{mmHg}$. Latanoprost (Xalatan ${ }^{\mathrm{TM}}$ ) was started and 1 month later IOP was reduced to $18 / 17 \mathrm{mmHg}$. However, the patient complained of reduced visual acuity, which was 20/50 in OD and 20/40 in OS. Fluorescein angiography disclosed CME in OU (Figure 2A and B) and latanoprost was discontinued. Dorzolamide-timolol solution $\left(\mathrm{Cosopt}^{\mathrm{TM}}\right)$ was started instead. After 1 month, vision returned to baseline values (20/30 in OD and 20/25 in OS) and IOP was $15 / 15 \mathrm{mmHg}$. Further in the follow-up a new fluorescein angiography did not show CME (Figure $2 \mathrm{C}$ and D).

\section{DISCUSSION}

In phases I and II studies of latanoprost, there was no reported case of CME in 380 patients whereas in phase III studies there were 2 reported cases of CME in 300 patients $^{(3)}$. In addition, 120 cases of CME associated with latanoprost have been spontaneously reported to Pharmacia as of June 1999, during which time an estimated 1.700 .000 patients had been treated with the $\operatorname{drug}^{(3)}$. Sum up to that several anecdotal case reports such as the ones we have described. The overall conclusion is that if there is an association between latanoprost use and CME it is certainly infrequent, even if it is underestimated, since many cases might have not been reported.

The rationale for development of CME due to latanoprost use is that the drug may lead to the disruption of the bloodaqueous barrier, and this barrier's breakdown, as measured by aqueous laser flare meter, has been significantly associated with development of CME in aphakic and pseudophakic eyes using latanoprost ${ }^{(4-5)}$. Interestingly, concurrent administration of nonsteroidal eyedrops seemed to prevent development of CME associated with latanoprost use in early postoperative pseudophakias $^{(4)}$.

Even tough the incidence of CME that could be attributable to latanoprost use is expected to be very low, it is known that aphakic and pseudophakic eyes, particularly those with open posterior capsule, are more likely to develop the side effect ${ }^{(3,6-8)}$. Furthermore, some investigators
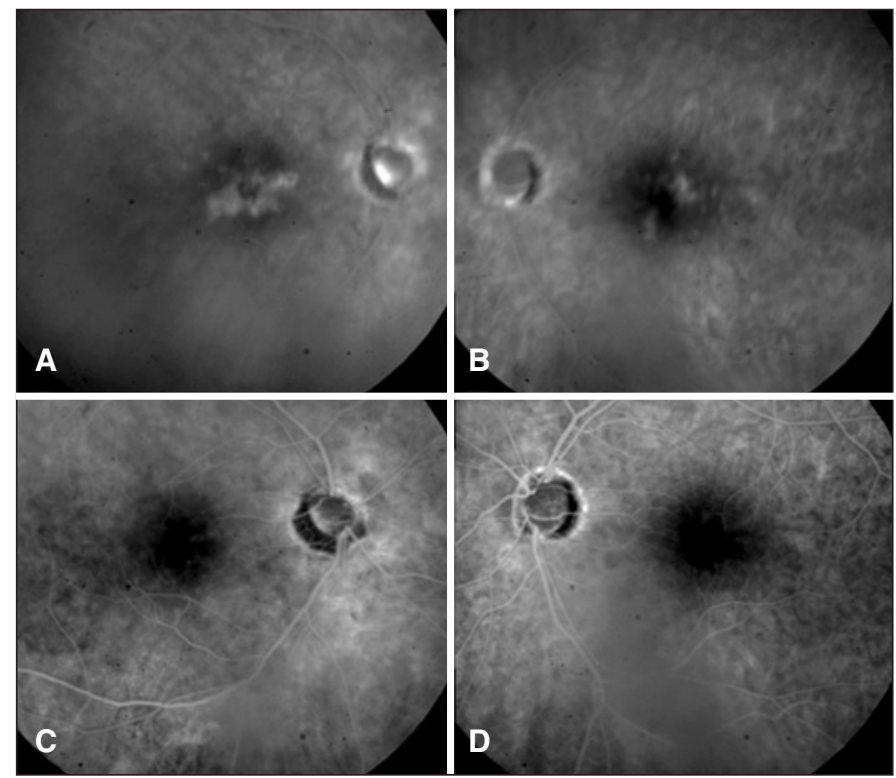

Figure 1 - Fluorescein angiography of the right eye ( $A$ and $C$ ) and the left eye (B and $D$ ). In A and B, 3 months after starting latanoprost eyedrops, late-phase angiography shows hyperfluorescence filling the cystic spaces with the characteristic stellate appearance of the cystoid macular edema. In C and D, after suspension of latanoprost eyedrops, the normal fluorescence of the foveal avascular zone is observed.
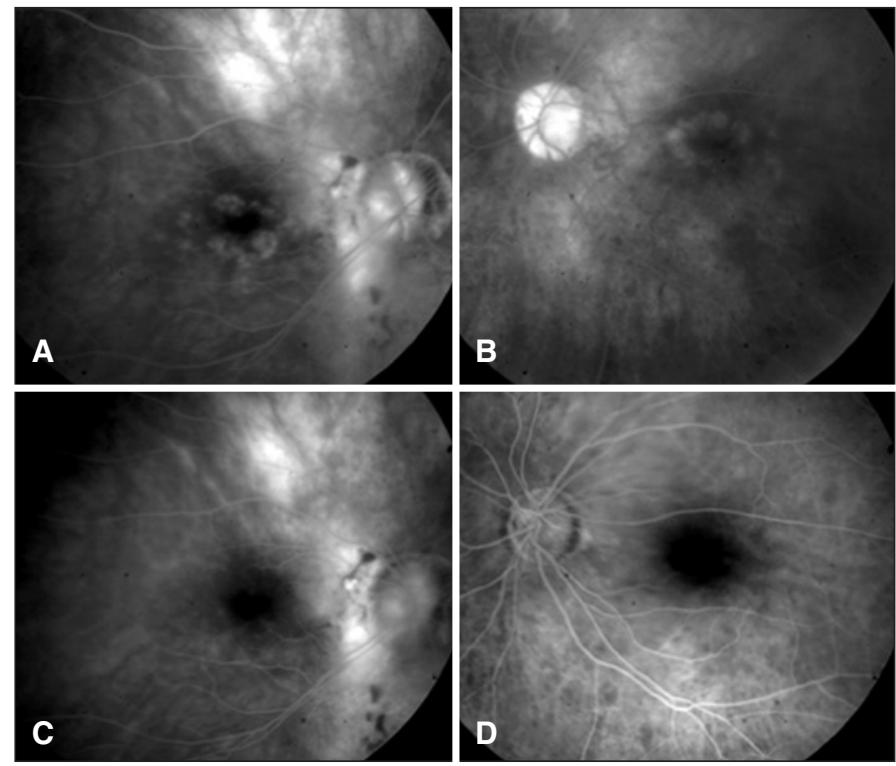

Figure 2 - Fluorescein angiography of the right eye (A and $C$ ) and the left eye (B and D). In A and B, after 1-month use of latanoprost eyedrops, fluorescein angiography discloses stellate hyperfluorescence in the macula, the typical presentation of cystoid macular edema. In C and $\mathrm{D}$, after latanoprost was discontinued, cystoid macular edema is no longer observed.

failed to show CME development in patients with normally functioning blood-ocular barrier ${ }^{(9)}$.

In case 1 hypotony maculopathy was discarded since it typically follows filtration surgery and is characterized by vision loss, retinal striae, choroidal folds, and no evidence of vascular leakage. In this case, there were no other clinical fea- 
tures of hypotony, such as shallow anterior chamber, Descemet's membrane striae, or serous choroidal detachment.

In the described cases, bilateral and simultaneous visually significant CME that could be attributable to latanoprost eyedrops were observed. Discontinuation of the drug led to improvement of vision to baseline values as well as to documented angiographic resolution of the CME in both cases. We believe it is important to raise awareness of this uncommon side effect in order to prevent any further vision loss in our glaucoma patients.

\section{RESUMO}

O edema macular cistóide é um efeito colateral incomum, porém bem conhecido, do latanoprost. São descritos dois casos de edema macular cistóide bilateral e simultâneo associado ao uso de latanoprost, em que foi observada completa resolução do edema após a suspensão da droga.

Descritores: Mácula lútea; Edema macular; Glaucoma; Prostaglandina F, synthetic; Relatos de casos ; Humanos; Adultos

\section{REFERENCES}

1. Holló G. The side effects of the prostaglandin analogues. Expert Opin Drug Saf. 2007;6(1):45-52

2. Wand M, Shields BM. Cystoid macular edema in the era of ocular hypotensive lipids. Am J Ophthalmol. 2002;133(3):393-7. Comment in: Am J Ophthalmol. 2002;133(3):403-5.

3. Schumer RA, Camras CB, Mandahl AK. Latanoprost and cystoid macular edema: is there a causal relation? Curr Opin Ophthalmol. 2000;11(2):94-100.

4. Miyake K, Ota I, Maekubo K, Ichihashi S, Miyake S. Latanoprost accelerates disruption of the blood-aqueous barrier and the incidence of angiographic cystoid macular edema in early post-operative pseudophakias. Arch Ophthalmol. 1999; 117(1):34-40. Comment in: Arch Ophthalmol. 1999;117(9):1265-6.

5. Arcieri ES, Santana A, Rocha FN, Guapo GL, Costa VP. Blood-aqueous barrier changes after the use of prostaglandin analogues in patients with pseudophakia or aphakia: a 6-month randomized trial. Arch Ophthalmol. 2005;123(2):186-92.

6. Suzanna Jr R. Incidência de edema macular cistóide com o uso de Xalatan em afácicos e pseudo-fácicos. Rev Bras Oftalmol. 1998;57(4):267-9.

7. Lima MC, Paranhos A Jr, Salim S, Honkanen R, Devgan L, Wand M, et al. Visually significant cystoid macular edema in pseudophakic and aphakic patients with glaucoma receiving latanoprost. J Glaucoma. 2000;9(4):317-21.

8. Wand M, Gaudio AR, Shields MB. Latanoprost and cystoid macular edema in high-risk aphakic or pseudophakic eyes. J Cataract Refract Surg. 2001;27(9) : 1397-401.

9. Furuichi M, Chiba T, Abe K, Kogure S, Iijima H, Tsukahara S, et al. Cystoid macular edema associated with topical latanoprost in glaucomatous eyes with a normally functioning blood-ocular barrier. J Glaucoma. 2001;10(3):233-6. 